\title{
The Explanatory Factors of Forced Vital Capacity of Primary Lung Cancer Patients Who Underwent Lung Resections
}

\section{Rabindra Nath Das ${ }^{1 *}$ and Youngjo Lee ${ }^{2}$}

${ }^{1}$ Department of Statistics, University of Burdwan, Burdwan, West Bengal, India

${ }^{2}$ Department of Statistics, College of Natural Science, Seoul National University, Seoul, 151-747, Korea

Surgery plays a vital role in the staging, diagnosis, and exact management of non-small cell lung cancer (NSCLC). Lung resection gives the highest probable of cure for localized primary lung cancer patients, which is correlated with a risk of decreased postoperative lung function, mortality, and other complications [1,2]. The European Respiratory Society of Thoracic Surgeons, the British Thoracic Society, and the American College of Chest Physicians guidelines give a detailed instructions for preoperative risk assessment, but their recommendations differ in somewhat $[3,4]$. The most important criteria of fitness for lung resections surgery are:

- Age (Younger age is more preferable).

- Pulmonary function (A preoperative forced expiratory volume in 1 second (FEV1) of $>1.5$ litre for lobectomy, and $>2.0$ litre for pneumonectomy generally indicates suitability for surgery or consequently forced vital capacity (FVC) is very high).

- Cardiovascular fitness (normal echocardiogram).

- Nutrition and Performance status; and in terms of operability to be.

- Diagnosis and Staging (patients are considered for surgery if they have a plain chest radiograph and a computed tomographic scan of the thorax including the liver and adrenal glands).

- Adjuvant therapy (patients with stage I (cT1N0 and cT2N0) and stage II (cT1N1, cT2N1 and cT3N0) tumours are considered operable).

- The operations available (sublobar resection is an important option for lung cancer patients with impaired pulmonary reserve).

- Locally advanced disease (for each patient with locally advanced disease, the management should be pointed at multidisciplinary meetings involving surgeons, physicians, and oncologists).

- Small cell lung cancer (surgery is appropriate treatment for stage I small cell lung cancer) $[5,6]$.

It is stated in above that the preoperative FEV1 $(>1.5$ litre for lobectomy, and $>2.0$ litre for pneumonectomy) (or FVC) should be very high for suitability of lung surgery. However, lower values invite further investigation of respiratory function. Therefore, the fundamental hypothesis is: what are the factors that increase or decrease the values of FEV1 and FVC? In the present report, we examine the above hypothesis for FVC with a real example. Note that FVC indicates the amount of air that a person can forcefully and quickly exhale after taking a deep breath, FEV1 shows the amount of air that a person can forcefully exhale in one second of the FVC test. The present report is based on the data set which was collected at Wroclaw Thoracic Surgery Centre for primary lung cancer patients who underwent major lung resections during the years 2007 to 2011 . The center is related with the Thoracic Surgery Department of the Medical University of Wroclaw and LowerSilesian Centre for Pulmonary Diseases, Poland, while the research database is a part of the National Lung Cancer Registry, controlled by the Institute of Tuberculosis and Pulmonary Diseases in Warsaw, Poland. The data set is given in UCI Machine Learning Repository. The data set contains 470 subjects with 17 study characters. The data set is clearly described in [7]. For ready reference, the variables and factors in the data set is reproduced herein. The factors and variables are:

- Diagnosis (DGN)-specific combination of ICD-10 codes for primary $(=1)$, secondary $(=2)$ and multiple tumor's $(=3)$ if any (DGN3, DGN2, DGN4, DGN6, DGN5, DGN8, DGN1)

- Forced vital capacity (FVC)

- Volume that has an exhaled at the end of the first second of forced expiration (FEV1)

- Performance status in Zubrod scale (PRZ) $(P R Z 2=3, P R Z 1=2$, $\mathrm{PRZ0}=1)$

- $\quad$ Pain before surgery (PBS) (True $(\mathrm{T})=2$, False $(\mathrm{F})=1$ )

- Haemoptysis before surgery (HBS) $(\mathrm{T}=2, \mathrm{~F}=1)$

- Dyspnoea before surgery (DBS) $(\mathrm{T}=2, \mathrm{~F}=1)$

- Cough before surgery (CBS) $(\mathrm{T}=2, \mathrm{~F}=1)$

- Weakness before surgery (WBS) $(\mathrm{T}=2, \mathrm{~F}=1)$

- Size of the original tumour (SOT) (OC11=1 (smallest), $\mathrm{OC} 12=2, \mathrm{OC} 13=3, \mathrm{OC}=14=4$ (largest)

- Diabetes mellitus (DM) (Type 2) $(\mathrm{T}=2, \mathrm{~F}=1)$

- Myocardial infraction (MI) up to 6 months $(\mathrm{T}=2, \mathrm{~F}=1)$

- Peripheral arterial disease $(\mathrm{PAD})(\mathrm{T}=2, \mathrm{~F}=1)$

*Corresponding author: Rabindra Nath Das, University of Burdwan, West Bengal, India, E-mail: rabin.bwn@gmail.com

Received September 19, 2018; Accepted September 22, 2018; Published September 30, 2018

Citation: Das RN, Lee Y (2018) The Explanatory Factors of Forced Vital Capacity of Primary Lung Cancer Patients Who Underwent Lung Resections. J Biomol Res Ther 7: e161. doi:10.4172/2167-7956.1000e161

Copyright: (c) 2018 Das RN, et al. This is an open-access article distributed under the terms of the Creative Commons Attribution License, which permits unrestricted use, distribution, and reproduction in any medium, provided the original author and source are credited. 
- Smoking status (SMOK) $(\mathrm{T}=2, \mathrm{~F}=1)$

- Asthma $(\mathrm{T}=2, \mathrm{~F}=1)$

- $\quad$ Age at surgery

- One year survival period after surgery (SURV) $(\mathrm{T}=2, \mathrm{~F}=1)$. For the above factors, we have identified the factors which have positive or negative association with FVC.

The response FVC is continuous, positive, heteroscedastic, and non-normally distributed. It may be analyzed by using joint generalized linear (JGL) Log-normal and Gamma models [8-11]. Based on both the analyses, the following reports have been presented very shortly. Details results will be discussed in our subsequent article. Here FVC is considered as the dependent variable, and the remaining others are considered as the explanatory variables. Note that joint generalized linear Log-normal models give better results than joint Gamma models, and the fitted JGL Log-normal models interpret the following.

- Age $(\mathrm{P}=0.003)$ is negatively associated with the mean FVC, implying that FVC is higher at younger ages than older. So, lung resection surgery is more suitable at younger ages.

- Haemoptysis before surgery $(\mathrm{T}=2, \mathrm{~F}=1)(\mathrm{P}=0.035)$ is negatively associated with the mean FVC, implying that lung cancer patients with no Haemoptysis have higher FVC than the patients with Haemoptysis.

- Diabetes mellitus Type $2(\mathrm{DM} 2)(\mathrm{T}=2, \mathrm{~F}=1)(\mathrm{P}=0.028)$ is negatively associated with the mean FVC, implying that lung cancer patients with no DM2 have higher FVC than the patients with DM2.

- Asthma $(\mathrm{T}=2, \mathrm{~F}=1)(\mathrm{P}<0.001)$ is negatively associated with the mean FVC, implying that lung cancer patients with no Asthma have higher FVC than the patients with Asthma.

- Cough before surgery $(\mathrm{T}=2, \mathrm{~F}=1)(\mathrm{P}=0.067)$ is partially positively associated with the mean FVC. It shows that FVC is higher for lung cancer patients with Cough than the patients without Cough.

- Performance status (PRZ) (PRZ2=3, PRZ1=2, PRZ0=1) at (PRZ1) $(\mathrm{P}=0.043)$ is negatively associated with the mean FVC, indicating that lung cancer patients with PRZ0 have higher FVC than the patients with PRZ2.

- Diagnosis (DGN) $(\mathrm{P}=0.003)$ is positively associated with the mean $\mathrm{FVC}$, indicating that FVC increases with the increased of DGN.
From the above it is observed that younger lung cancer patients with no diabetes mellitus, no asthma, no haemoptysis have higher FVC. There are many more explanatory parameters of the variance of FVC. For lung cancer patients with advanced diseases should be treated very carefully.

\section{Conflict of Interest}

The authors confirm that this article content has no conflict of interest.

\section{Acknowledgement}

This research was supported by the Brain Research Program through the National Research Foundation of Korea (NRF) funded by the Ministry of Science ICT \& Future Planning (2014M3C7A1062896).

\section{References}

1. Lackey A, Donington JS (2013) Surgical Management of Lung Cancer. Semin Intervent Radiol 30: 133-140.

2. Rocco G, Internullo E, Cassivi SD, Van Raemdonck D, Ferguson MK, et al (2008) The variability of practice in minimally invasive thoracic surgery for pulmonary resections. Thorac Surg Clin 18: 235-247.

3. Mountain CF (1997) Revisions in the international system for staging lung cancer. Chest 111: 1710

4. Harada H, Okada M, Sakamoto T, Matsuoka H, Tsubota N, et al. (2005) Functional advantage after radical segmentectomy versus lobectomy for lung cancer. Ann Thorac Surg 80: 2041-2045.

5. Cerfolio RJ, Bryant AS (2007) Surgical techniques and results for partial or circumferential sleeve resection of the pulmonary artery for patients with nonsmall cell lung cancer. Ann Thorac Surg 83: 1971-1976.

6. Cukic V, Baljic R (2012) The Most Common Detected Risk and Etiologic Factors of Pulmonary Thromboembolism. Mat Soc Med 24: 223-226.

7. Zieba M, Tomczak JM, Lubicz M, Swiatek J, Boosted SVM, et al. (2014) For extracting rules from imbalanced data in application to prediction of the postoperative life expectancy in the lung cancer patients. Applied Soft Computing 14: 99-108.

8. Das RN, Lee Y (2009) Log-normal versus gamma models for analyzing data from quality-improvement experiments. Quality Engineering 21: 79-87.

9. Das RN, Lee $Y(2010)$ Analysis strategies for multiple responses in quality improvement experiments. Inter J Quality Engineering and Technology 1: 395-409.

10. Das RN (2017) Forced expiratory volume factors of stage III non-small cell lung cancer patients. Arch Gen Intern Med 1: 3-7.

11. Das RN, Mukherjee S (2017) Mean-variance overall survival time fitted models from stage III non-small cell lung cancer. Epidemiology (Sunnyvale) 7: 296. 